\title{
Lofty frequency and reproducible plant regeneration from mature nodal explants of "Egusi"melon (Citrullus colocynthis L.)
}

\author{
Prabhu Thangavel ${ }^{1 *}$, Sisubalan Natarajan ${ }^{2,3}$, Velmurugam Shanmugam ${ }^{1}$, \\ SHEIK MOHAMEd SUlaiman ${ }^{1}$, RAVIKUMAR RAMASAMY ${ }^{1}$ \\ ${ }^{1}$ P.G. and Research Department of Botany, Jamal Mohamed College (Autonomous), \\ Khaja Nagar, Tamil Nadu, India \\ ${ }^{2}$ P.G. and Research Department of Botany, J.J. College of Arts and Science (Autonomous), \\ Pudukkottai, Tamil Nadu, India \\ ${ }^{3}$ Key Laboratory of Molecular Epigenetics of MOE and Institute of Genetics and Cytology, \\ Northeast Normal University, Changchun, China
}

\begin{abstract}
The present study attempts to explain a mass culture protocol for large scale multiple shoot bud regeneration from nodal explants of Citrullus colocynthis L. The highest shoot bud induction (94.9\%) without attaining callus was observed in Murashige and Skoog's (MS) medium supplemented with benzyl amino purine (BA)in which the combination of benzyl amino purine BAP $(1.0 \mathrm{mg} / \mathrm{l})$, kinetin $(0.5 \mathrm{mg} / \mathrm{l})$, gibberellic acid $(1.5 \mathrm{mg} / \mathrm{l})$ produced more shoots/explants. This study strongly suggests that the pre-eminence of BA and other cytokinins in combination with $\mathrm{GA}_{3}$ was found to be essential for a swift multiple shoot bud induction as well as an enhanced rate of shoot proliferation in $C$. colocynthis. A full-strength MS medium, supplemented with indole 3 butyric acid IBA (1.5 mg/l) combined with $\mathrm{BA}(1.5 \mathrm{mg} / \mathrm{l})$, had the maximum rooting response and the regenerated plantlets were successfully established in the field with an $80 \%$ survival rate.
\end{abstract}

Key words: nodal explants, surface sterilization, mercuric chloride, shoot bud, BA, multiple shoot, IBA, GA rooting

\section{Introduction}

The plant Citrullus colocynthis (Cucurbitaceae), indigenous to India, Pakistan, and Sri Lanka has a variety of biological properties, including anticancer, antidiabetic, anti-inflammatory, cytotoxic, antioxidant, insecticidal, antilipidemic, antimicrobial, powerful cathartic and abortifacient properties, and ethnomedical claims (da Silva and Hussain, 2017; Hussain et al, 2014; Afifi et al, 1999) and can also be used in the treatment of amenorrhea, (Atta-UrRahman et al, 1973). The fruit extracts of $C$. colocynthis have been shown to possess cytotoxic, antitumor, and cardiac depressant properties, and are a smooth muscle relaxant (Meena et al., 2010; Gallily et al., 1962) facilitating easy maternal delivery in humans, for which the root base is mixed with cow's milk and applied over the hypogastrium (Yadav et al., 2006). The Cucurbitaceae family mostly includes prostrate or climbing herbaceous annuals comprising about 125 genera and 960 species, including melons, and gourds like cucumbers. The family is predominantly distributed around the tropics, mostly as edible fruits. The miscellany of cucurbitacin properties, especially antibacterial, cytotoxic, and antifeedant properties, is good basis for further investigations (Elrofaei et al., 2018; Miró, 1995; Lavie and Glotter, 1971).

Cucurbitaceae members grow under a wide range of agroclimatic and soil conditions, but diseases and pests significantly affect the yield of this important crop. There is a serious pharmaceutical demand for speedy

\footnotetext{
* Corresponding author: P.G. and Research department of Botany, Jamal Mohamed College (Autonomous), Post Box No. 808, 
production of these plants (Vengadesan et al., 2005; Grozeva and Velkov, 2014; Venkatachalam et al., 2018). Importantly, overexploitation and deteriorating environmental conditions are critical threats to wild Cucurbitaceae members. Because of their versatile applications, there is rising interest world over in increasing the productivity of Cucurbitacins using commercial and conventional cultivation methods (Zhao et al., 2018).

Conventional tissue culture methods like plant tissue culture produce a large number of plants within a short period of time and may alter the genetic setup of plants; therefore, they are recommended for overcoming yield losses due to biotic and abiotic factors. They can produce disease resistant, drought resistant, and stress resistant plants in a small space (Kumar et al., 2015; Venkatachalam et al., 2018). For effective large scale production and ensuring productivity, a stable and fast growing perpetual explant source is required. Cucurbitaceae have developed a regeneration system through complete organogenesis using various explant sources such as nodal segments (Ahmad and Anis, 2005; Kontas and Kintzios, 2003), embryonal axis (Vasudevan et al., 2007), cotyledons (Gambley and Dodd, 1990; Selvaraj et al., 2007), shoot tips (Vasudevan et al., 2004) and hypocotyls (Selvaraj et al., 2006).

The present research focused on developing an efficient and rapid propagation protocol for $C$. colocynthis to fulfill the market demand of the medicinal and pharmaceutical industries. This is the first attempt to study the effect of different growth regulators on the in vitro organogenesis of $C$. colocynthis using mature nodal explant sources. The improved method of plant regeneration in $C$. colocynthis that has been established could be applied in large scale propagation and also to ensure a continuous supply of plants produced in limited time and space through ex vitro rooting for the production of vital compounds. It may be useful in commercial (pharmaceutical) industries too.

\section{Materials and methods}

\section{Plant material}

The mature nodal explants of wild-grown $C$. colocynthis L. were collected from 2-3-month-old plants and washed in running tap water followed by washing with water with a few drops of $10 \%(\mathrm{v} / \mathrm{v})$ Tween-20 to remove exterior dust particles and microbes. Afterwards, the surface was sterilized with $0.1 \%(\mathrm{w} / \mathrm{v})$ mercuric chloride solution for 1.5-2 min followed by rinsing five times with sterile double-distilled water.

\section{Culture media conditions}

Sterilized nodal explants $(10 \mathrm{~mm})$ were inoculated onto Murashige and Skoog's (1962) solid medium containing $3 \%(\mathrm{w} / \mathrm{v})$ sucrose with different concentrations of growth regulators used for shoot and multiple-shoot induction. The hormonal composition was selected on the basis of earlier reports (Vivekanandan et al., 2014; Sheik Mohamed et al., 2017). The $\mathrm{pH}$ of the medium was adjusted to 5.6 with $0.1 \mathrm{~N}$ sodium hydroxide $(\mathrm{NaOH})$ or hydrochloric acid $(\mathrm{HCl})$ before adding agar $(0.8 \%(\mathrm{w} / \mathrm{v}))$. The media (15 ml) were dispersed into $25 \mathrm{~mm} \times 150 \mathrm{~mm}$ culture tubes (Borosil, Mumbai), and autoclaved (20 $\mathrm{min}$ at $\left.121^{\circ} \mathrm{C} ; 1.4 \times 104 \mathrm{~kg} \cdot \mathrm{m}^{-2}\right)$. All the cultures were incubated at $25 \pm 2^{\circ} \mathrm{C}$, with a $16 \mathrm{~h}$ photoperiod $\left(50 \mu \mathrm{mol} \cdot \mathrm{m}^{-2} \mathrm{~s}^{-1}\right)$.

\section{Influence of plant growth regulators on shoot and multiple-shoot proliferation}

The individual nodal explants were placed vertically in each culture tube. The hormonal concentration was selected based on earlier reports (Meena et al., 2010); each tube contained MS medium supplemented with different concentrations $(0.2-2.5 \mathrm{mg} / \mathrm{l})$ of 2-benzyl amino purine (BA) and kinetin (KIN) (Table 1). After four weeks of culture initiation, the efficacy of cytokinins on shoot proliferation was recorded as: A) the rate of recurrence of primary explants developing per shoot and B) the total number of shoots per explant. A multipleshoot induction was observed from the cut shoot apex after 15 days of culture initiation (Singh et al., 2012).

\section{Shoot bud elongation and multiplication}

The explants with shoot clusters, after four weeks of culture on plant growth regulator (PGR) fortified media, were subcultured on full or half strength MS basal medium without PGR or supplemented with varied concentrations $(0.05-2.0 \mathrm{mg} / \mathrm{l})$ of Gibberellic acid $\left(\mathrm{GA}_{3}\right)$ (Table 2) to allow for the elongation of the shoot buds. The frequency of elongation, the mean shoot length and the mean number of nodes per shoot were recorded after four weeks of culture (Singh et al, 2012). To attain shoot bud multiplication and elongation, two experiments were conducted. In the first experiment, the in vitro derived shoot buds were cultured on MS medium fortified with 
Table 1. Effect of different concentrations of two cytokinins on the initiation of shoot buds from mature axillary node explants of Citrullus colocynthis

\begin{tabular}{c|c|c|c|c}
\hline \multicolumn{2}{c|}{$\begin{array}{c}\text { Cytokinin } \\
\text { concentration } \\
{[\mathrm{mg} / \mathrm{l}]}\end{array}$} & $\begin{array}{c}\text { Percentage } \\
\text { of shoot bud initiation } \\
\text { (mean } \pm \text { SE) }\end{array}$ & $\begin{array}{c}\text { Number } \\
\text { of shoots/explants } \\
\text { (mean } \pm \text { SE) }\end{array}$ & $\begin{array}{c}\text { Shoot length } \\
\text { [cm] } \\
\text { (mean } \pm \text { SE) }\end{array}$ \\
\hline BAP & KIN & $33.33 \pm 0.57$ & $2.83 \pm 0.57$ & $1.90 \pm 1.00$ \\
\hline 0.5 & & $61.11 \pm 0.58$ & $4.50 \pm 0.57$ & $3.12 \pm 1.16$ \\
\hline 1.0 & & $77.77 \pm 0.58$ & $6.10 \pm 0.58$ & $4.56 \pm 1.00$ \\
\hline 1.5 & & $94.44 \pm 0.54$ & $7.96 \pm 1.15$ & $6.92 \pm 1.53$ \\
\hline 2.0 & & $66.66 \pm 1.52$ & $4.88 \pm 0.57$ & $5.12 \pm 1.00$ \\
\hline 3.5 & & $50 \pm 1.52$ & $4.10 \pm 1.00$ & $4.33 \pm 1.00$ \\
\hline & 0.5 & $44.44 \pm 0.57$ & $3.61 \pm 0.58$ & $1.30 \pm 1.00$ \\
\hline & 1.0 & $72.22 \pm 0.58$ & $4.72 \pm 1.00$ & $2.43 \pm 0.58$ \\
\hline & 1.5 & $88.88 \pm 0.58$ & $5.83 \pm 1.16$ & $4.88 \pm 1.15$ \\
\hline & 2.0 & $66.66 \pm 1.00$ & $5.11 \pm 1.15$ & $3.01 \pm 0.58$ \\
\hline & 3.0 & $38.88 \pm 1.15$ & $3.13 \pm 0.57$ & $2.11 \pm 0.52$ \\
\hline
\end{tabular}

SE - standard error, KIN - Kinetin, BAP - benzyl amino purine

Table 2. Effect of different concentrations of $\mathrm{GA}_{3}$ and various concentrations of $\mathrm{BAP}(0.5-3.0 \mathrm{mg} / \mathrm{l})$ in combination with $0.5 \mathrm{mg} / \mathrm{l} \mathrm{KIN}$ and $1.0 \mathrm{mg} / 1 \mathrm{GA}_{3}$ for multiple shoot-bud induction as well as shoot-bud elongation of $C$. colocynthis

\begin{tabular}{|c|c|c|c|c|c|}
\hline \multicolumn{3}{|c|}{$\begin{array}{c}\text { Hormone } \\
\text { concentration } \\
{[\mathrm{mg} / \mathrm{l}]}\end{array}$} & \multirow{2}{*}{$\begin{array}{l}\text { Percentage } \\
\text { of response } \\
(\text { mean } \pm \mathrm{SE})\end{array}$} & \multirow{2}{*}{$\begin{array}{c}\text { Number } \\
\text { of shoots/culture } \\
(\text { mean } \pm \mathrm{SE})\end{array}$} & \multirow{2}{*}{$\begin{array}{l}\text { Shoot length } \\
{[\mathrm{cm}]} \\
(\text { mean } \pm \mathrm{SE})\end{array}$} \\
\hline BAP & KIN & $\mathrm{GA}_{3}$ & & & \\
\hline & & 0.5 & $38.88 \pm 1.53$ & $2.81 \pm 0.58$ & $3.92 \pm 1.53$ \\
\hline & & 1.0 & $55.5 \pm 1.53$ & $3.44 \pm 1.00$ & $4.56 \pm 0.58$ \\
\hline & & 1.5 & $72.22 \pm 0.58$ & $4.56 \pm 1.53$ & $5.98 \pm 1.00$ \\
\hline & & 2.0 & $83.33 \pm 0.99$ & $5.92 \pm 0.58$ & $7.01 \pm 1.15$ \\
\hline & & 2.5 & $61.11 \pm 1.16$ & $3.22 \pm 1.00$ & $6.10 \pm 2.00$ \\
\hline 0.5 & 0.5 & 1.0 & $55.55 \pm 1.15$ & $10.11 \pm 0.58$ & $3.01 \pm 1.00$ \\
\hline 1.0 & 0.5 & 1.0 & $88.88 \pm 1.00$ & $13.96 \pm 0.58$ & $7.56 \pm 1.53$ \\
\hline 1.5 & 0.5 & 1.0 & $72.22 \pm 1.53$ & $11.32 \pm 0.99$ & $6.11 \pm 1.53$ \\
\hline 2.0 & 0.5 & 1.0 & $50 \pm 1.52$ & $10.01 \pm 1.00$ & $5.01 \pm 1.15$ \\
\hline 2.5 & 0.5 & 1.0 & $38.88 \pm 1.53$ & $8.62 \pm 0.57$ & $4.31 \pm 1.00$ \\
\hline 3.0 & 0.5 & 1.0 & $27.77 \pm 1.15$ & $7.32 \pm 1.15$ & $3.86 \pm 1.00$ \\
\hline
\end{tabular}

$\mathrm{SE}$ - standard error; $\mathrm{GA}_{3,}$ - gibberellic acid; $\mathrm{KIN}$ - kinetin, $\mathrm{BAP}$ - benzyl amino purine

various concentrations of $\mathrm{GA}_{3}(0.5-2.0 \mathrm{mg} / \mathrm{l})$ alone for shoot bud elongation. In the other experiment for shoot bud multiplication and elongation, the shoot buds were cultured on a medium containing various concentrations of BA $(0.5-3.0 \mathrm{mg} / \mathrm{l})$ in combination with $0.5 \mathrm{mg} / \mathrm{l} \mathrm{KIN}$ and $1.0 \mathrm{mg} / \mathrm{l} \mathrm{GA}_{3}$. 
Table 3. Effect of different concentrations and combinations of auxins and cytokinins on root induction from mature axillary nodal explants of $C$. colocynthis

\begin{tabular}{|c|c|c|c|c|c|c|c|}
\hline \multicolumn{5}{|c|}{$\begin{array}{l}\text { Hormone concentration } \\
{[\mathrm{mg} / \mathrm{l}]}\end{array}$} & \multirow{2}{*}{$\begin{array}{c}\text { Percentage of root } \\
\text { development } \\
(\text { mean } \pm \text { SE })\end{array}$} & \multirow{2}{*}{$\begin{array}{c}\text { Number } \\
\text { of roots/explant } \\
(\text { mean } \pm \text { SE })\end{array}$} & \multirow{2}{*}{$\begin{array}{l}\text { Root length } \\
{[\mathrm{cm}]} \\
(\text { mean } \pm \mathrm{SE})\end{array}$} \\
\hline BAP & IBA & NAA & IAA & KIN & & & \\
\hline 0.5 & & 0.5 & & & $44.44 \pm 1.53$ & $4.32 \pm 1.53$ & $3.13 \pm 1.53$ \\
\hline 1.0 & & 1.0 & & & $66.66 \pm 1.53$ & $5.12 \pm 1.53$ & $4.51 \pm 1.53$ \\
\hline 1.5 & & 1.5 & & & $88.88 \pm 2.08$ & $6.52 \pm 1.53$ & $5.86 \pm 1.53$ \\
\hline 2.0 & & 2.0 & & & $72.22 \pm 1.53$ & $5.01 \pm 1.53$ & $4.71 \pm 1.53$ \\
\hline 3.0 & & 2.5 & & & $55.55 \pm 1.53$ & $4.07 \pm 1.53$ & $3.63 \pm 1.53$ \\
\hline 0.5 & & & 2.5 & & $50 \pm 2.51$ & $5.61 \pm 1.52$ & $3.46 \pm 1.53$ \\
\hline 1.0 & & & 2.0 & & $72.22 \pm 1.53$ & $6.76 \pm 1.53$ & $4.88 \pm 1.53$ \\
\hline 1.5 & & & 1.5 & & $83.33 \pm 1.53$ & $7.96 \pm 1.53$ & $6.22 \pm 1.15$ \\
\hline 2.0 & & & 1.0 & & $66.66 \pm 1.53$ & $6.03 \pm 1.53$ & $5.03 \pm 1.53$ \\
\hline 3.0 & & & 0.5 & & $44.44 \pm 1.53$ & $4.11 \pm 1.53$ & $3.08 \pm 1.53$ \\
\hline 0.5 & & & & 0.5 & $61.11 \pm 1.16$ & $4.57 \pm 1.52$ & $2.96 \pm 0.58$ \\
\hline 1.0 & & & & 1.0 & $77.77 \pm 1.53$ & $5.32 \pm 1.53$ & $5.97 \pm 1.53$ \\
\hline 1.5 & & & & 1.5 & $88.88 \pm 1.53$ & $6.21 \pm 1.53$ & $6.01 \pm 1.53$ \\
\hline 2.0 & & & & 2.0 & $72.22 \pm 1.53$ & $5.10 \pm 1.53$ & $4.21 \pm 1.53$ \\
\hline 3.0 & & & & 2.5 & $38.88 \pm 1.53$ & $4.21 \pm 1.53$ & $3.12 \pm 1.53$ \\
\hline 0.5 & 2.5 & & & & $55.55 \pm 1.53$ & $7.13 \pm 1.53$ & $4.18 \pm 1.53$ \\
\hline 1.0 & 2.0 & & & & $77.77 \pm 1.53$ & $8.27 \pm 1.53$ & $5.33 \pm 1.53$ \\
\hline 1.5 & 1.5 & & & & $94.44 \pm 1.53$ & $9.53 \pm 1.53$ & $7.01 \pm 1.53$ \\
\hline 2.0 & 1.0 & & & & $66.66 \pm 1.53$ & $8.01 \pm 1.53$ & $6.59 \pm 1.53$ \\
\hline 3.0 & 0.5 & & & & $44.44 \pm 0.88$ & $6.14 \pm 1.53$ & $5.17 \pm 1.53$ \\
\hline
\end{tabular}

SE - standard error; BAP - benzyl amino purine, IBA - indole-3-butyric acid, IAA - indole-3-acetic acid, KIN - kinetin

\section{Rooting and acclimatization}

The elongated shoots $(4-5 \mathrm{~cm})$ having 2 or 3 expanded leaves were excised and transferred to a root induction medium (Table3). Well-elongated shoots were transferred to a full or half-strength MS medium without PGR or fortified with IAA $(0.5-2.5 \mathrm{mg} / \mathrm{l})$, indole-3-butyric acid (IBA) $(0.5-2.5 \mathrm{mg} / \mathrm{l})$, and naphthalene acetic acid (NAA) (0.5-2.5 mg/l) - Table 3. Plantlets with well-developed roots were excised from the culture tubes and, the roots were washed gently under running tap water and then the plantlets were cultured vertically on paper cups filled with sterilized soilrite. The cups were covered with transparent polythene bags and irrigated daily with $1-2 \mathrm{ml}$ of sterilized MS salt solution for six days, followed by irrigation with sterilized distilled water. The plants were maintained in the culture room at $25 \pm 2^{\circ} \mathrm{C}$ under $16 \mathrm{~h} /$ day illu- mination of $50 \mu \mathrm{mol} \cdot \mathrm{m}^{-2} \mathrm{~s}^{-1}$ provided by cool-white fluorescent tubes. After two weeks, the polythene bags were gradually removed and the plants were kept in the culture room for another two weeks. Further, the plantlets were transplanted into earthen pots containing garden soil and kept in shade in a net house for another two weeks before being transferred to field conditions.

\section{Statistical analysis}

Experiments were set up in a completely randomized block design and each experiment usually had three replicates. There were 20 culture tubes containing a single explant per replicate. The analysis of variance (ANOVA) was carried out to detect the significance of differences among the treatment means. Comparison among the mean values of treatments was made using Duncan's 
multiple range test at the $5 \%$ level of probability (Gomez and Gomez, 1984).

\section{Results and discussion}

\section{Plant material and multiple shoot induction}

In the present study, we obtained the maximum number of shoots and multiple shoot induction from mature nodal explants collected from wild-grown plants grown on MS solid medium supplemented with $2.0 \mathrm{mg} / \mathrm{l}$ of BA and $1.5 \mathrm{mg} / 1 \mathrm{KN}$ alone. Researchers have experimented with diverse explants like cotyledons, single buds, shoot tips, leaves, axillary buds, and nodes from a variety of over-exploited medicinal plants using solid MS media for mass production but nodal explants were produced efficiently in C. colocynthis (Sen and Sharma, 1991; Kulkarni et al., 1996, 2000; Furmanowa et al., 2001; Sivanandhan et al., 2011; Malayaman et al., 2017).

\section{Influence of plant growth regulators on shoot and multiple shoot proliferation}

To determine the perfect conditions for producing the maximum number of shoots and plantlets, the experiments were repeated thrice. The maximum number of shoots and multiple shoots obtained is shown in Table 1 and Figure 1. Among the various cytokinins applied, MS medium fortified with only $2.0 \mathrm{mg} / \mathrm{l} \mathrm{BA}$ was the most efficient for shoot production and multiplication (94.44 \pm 0.54 of shoots). Cytokinins used in our study are known to eoxgenously improve the development of axillary meristems, enhance proliferation of meristematic cells in axillary buds and augment the number of bud primordia from the pre-existing meristems (Carmen et al., 2001).

In the present study, multiple shoot proliferation was achieved due to the dependable contact with and increased amalgamation of BA by the shoots growing in MS medium (Table 1). It was found that multiple shoot generation was synergistically increased by manipulating the balance of cytokinins. Cytokinins play an important role in shoot regeneration and multiplication due to the formation of de novo (and pre-existing) meristems from nodal explants of medicinal plants in a solid system in Withania somnifera (Sivanandhan et al., 2011) and Ammania baccifera (Sheik Mohamed et al., 2017). The superiority of BAP for shoot bud induction has also been well-documented in Citrullus lanatus, where the number of shoots per explant was observed to be $5.22 \pm 0.54^{\text {b }}$, the shoot length recorded was $2.58 \pm 0.37^{\mathrm{b}}$ (Pirinc et al., 2003). Moreover, shooting response of $93 \%$ with 19.80 shoots per explant was recorded in $C$. lanatus by Ganesan and Huyop (2010), and in Cucumis sativus, shoot bud regeneration recorded was up to $96.4 \%$ with 11.4 shoots/(explant) culture (Venkatachalam et al., 2018). Ntui et al. (2009) stated that BAP alone enhanced shoot bud induction and elongation in $C$. colocynthis up to $86.3 \%$, with $1.5 \pm 0.4^{\mathrm{bc}}$ number of shoots.

The present study involved inoculating the shoots with a high concentration (results not shown) of individual cytokinins and was focused on altering the morphology of multiple shoots by, for example, the shortening or lengthening the internode, differentiating between smaller and bigger leaves, suppressing the shoots or reducing the proliferation rate. Therefore, the initiated adventitious shoot buds were further subcultured onto a fresh medium containing the same concentrations of $\mathrm{BAP}$ alone and/or in combination with NAA/IBA for the enhancement of a multiple shoot-bud regeneration. This was supported by Venkatachalam et al. (2018) in C. sativus $\mathrm{L}$ and Kulkarni et al. (2000) in W. somnifera. Sen and Sharma (1991) recorded 145 shoots/shoot tips and 120 shoots/shoot tips respectively on BA with IBA, and BA with 2,4-D supplemented on a solid medium in $W$. somnifera with $8 \pm 2.1$ number of shoots. Similarly, 120 shoots from a single bud in the Nitsch and Nitsch (1969) solid medium fortified with BA and IBA were obtained in $W$. somnifera by Furmanowa et al. (2001). Ray and Jha (2001) obtained 37 microshoots/shoot tip explants in MS liquid medium supplemented with BA and coconut water. Likewise, it has been reported that $\mathrm{BA}$ at the minimum concentration $(0.5 \mathrm{mg} / \mathrm{l}$ to $1.5 \mathrm{mg} / \mathrm{l})$ was found to be optimal for a multiple shoot-bud initiation/induction from mature nodal explants of $C$. sativus (Ahmad and Anis, 2005). However, the highest number of multiple shoots in cucumber was attained in MS medium containing a combination of $\mathrm{BA}(3.0 \mathrm{mg} / \mathrm{l})$ and IAA $(0.5 \mathrm{mg} / \mathrm{l})$ by Ugandhar et al. (2011), with $70 \%$ shoot induction and $3.8 \pm 0.36$ shoots/explant in Cucumis sativum, by Grozeva and Velkov (2014) with $76.7 \%$ success rate, by Jesmin and Mian (2016) with $73.05 \pm 2.1 \%$ success rate and $96.4 \%$ with 11.4 shoots/explant in $C$. sativus by Venkatachalam et al. (2018). Most of the above discussed results were not superior to our results with $94.44 \pm 0.54$ shoots/ explant. 

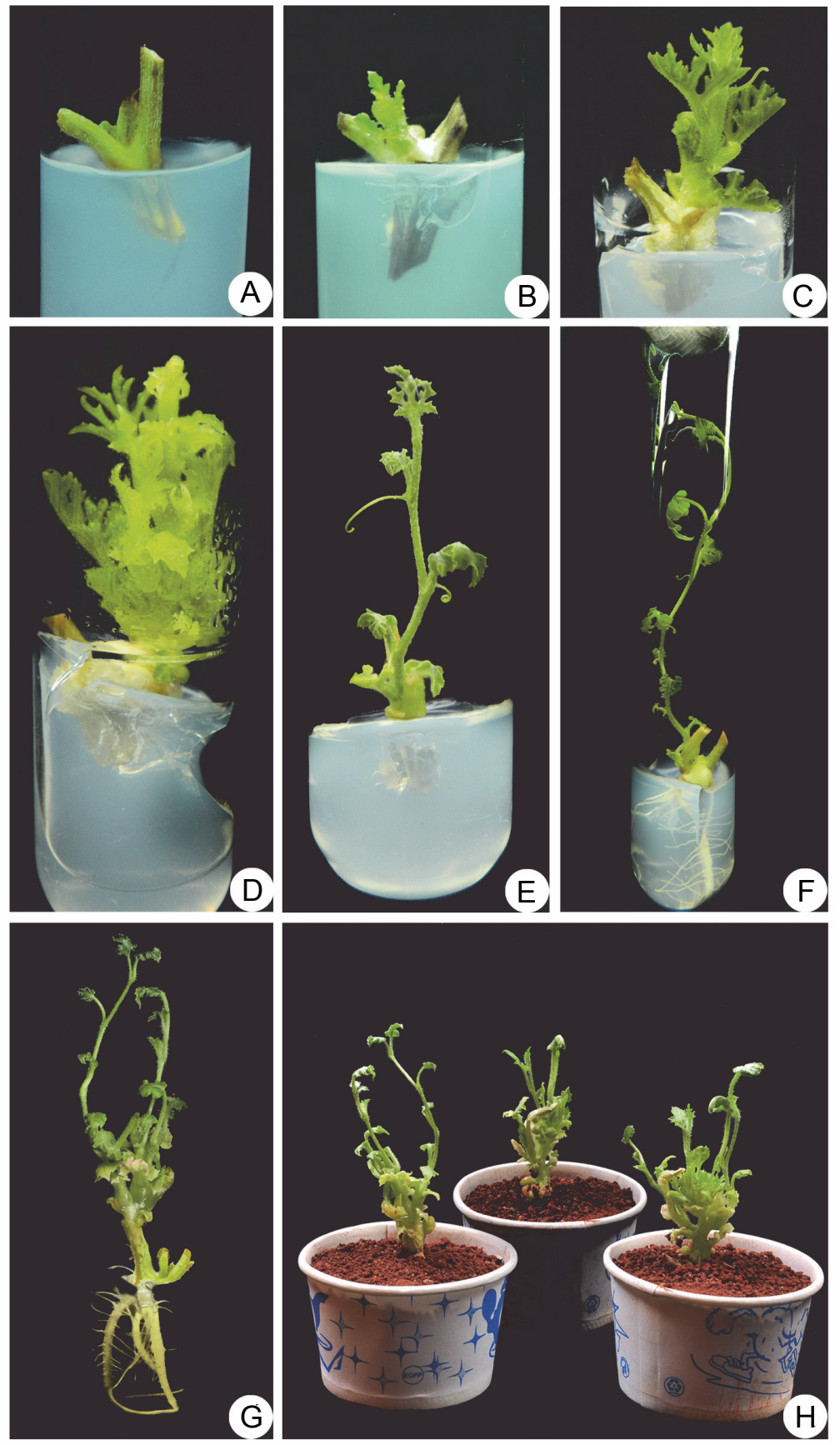

Fig. 1. Plant regeneration from mature nodal explant of Citrullus colocynthis L.: A) nodal explant of $C$. colocynthis; B) shoot initiation from nodal explant; C) shoot proliferation; D) multiple shoot proliferation; E) elongation of shoot on full strength MS media; F) in vitro rooting of regenerated shoot; G) complete plantlet and well developed root system; H) acclimatized plants on sterile soil

\section{Effect of $M S$ strength and $G_{3}$ concentration on shoot elongation}

Shoot elongation in regenerated plantlets is a crucial step of culturing in vitro which requires alteration in media composition (Malik and Saxena, 1992; Prakash et al., 1994), plant growth regulator substitution (Mohamed et al., 1991), change in light conditions etc. In the present study, multiple shoots developed on BA-containing media failed to elongate in the same medium. This 
result additionally suggested that genotype is considered as one of the main factors influencing the shoot bud regeneration rate and various genotypes needed different growth regulator combinations for plantlet development (Wang et al., 2015).

The number of multiple shoots was enhanced in a medium supplemented with BA alone and/or in combination with a lower dose of auxins to the highest value of $94 \%$. Similarly, the maximum amount (above $2.5 \mathrm{mg} / \mathrm{l}$ ) of BA over other cytokinins has been reported for Psoralea corylifolia and Withania coagulans shoot regeneration for the maximum production of shoot regeneration (Siva et al., 2015; Rathore et al., 2016). BA has frequently been reported to initiate shoot proliferation while inhibiting shoot elongation (Figueiredo et al., 2001; Brassard et al., 1996). Multiple shoots were developed on BA-fortified media and were further transferred to PGRfree full-strength and half-strength MS media to observe its impact on shoot elongation in C. colocynthis. For shoot elongation, a full-strength MS medium was found to be better than a half-strength MS medium. The desire shoot elongation rate, the length of shoots and the number of nodes per shoot were not achieved on a PGR-free medium.

It was crucial to choose the proper media for the elongation of shoots. $\mathrm{GA}_{3}$ at $0-2 \mathrm{mg} / \mathrm{l}$ (Table 2 ) was used in attempts to enhance shoot elongation. An addition of $1.0 \mathrm{mg} / \mathrm{l} \mathrm{GA}_{3}$ to the full-strength MS medium was found to be optimal for shoot longation (Fig. 1). ANOVA had showed the considerable effect on the shoot length and the number of nodes per shoot. The best shoot growth, in the form of shoot length $(7.56 \pm 1.53 \mathrm{~cm})$ and number (13.96 \pm 0.58$)$ of nodes per shoot, was achieved in MS medium fortified with $1.0 \mathrm{mg} / 1 \mathrm{GA}_{3}$, along with cytokinins BA $(1.0 \mathrm{mg} / \mathrm{l})$ and $\mathrm{KIN}(0.5 \mathrm{mg} / \mathrm{l})$. It was further suggested by Caldas et al. (2009) that $\mathrm{GA}_{3}$ alone or in combination with cytokinin promotes shoot elongation in several plants. Likewise, Prem Kumar et al. (2016) showed that BA had a greater effect on multiple shoot bud regeneration as well as shoot elongation in cotton when compared to KIN.

\section{Rooting}

In vitro grown shoots were excised separately and placed in MS medium supplemented with various concentrations of IAA, IBA, or NAA $(0.5-2.5 \mathrm{mg} / \mathrm{l})$ for root induction. The initial roots emerged directly from the basal parts of the shoots after 14 days of culture. The maximum root induction (94\%) was achieved in MS medium supplemented with $1.5 \mathrm{mg} / \mathrm{l} \mathrm{BA}$ and $1.5 \mathrm{mg} / \mathrm{l} \mathrm{IBA}$ (Fig. 1, Table 3). Increasing concentrations of IBA and IAA significantly increased the rooting percentage. Similar observations were made by Thiruvengadam and Jayabalan (2000), Arockiasamy et al. (2002), Raman and Jaiwal (2000) and Jeyakumar and Jayabalan (2002). The rooting response was negatively correlated with NAA concentrations and no root initiation was noted at a higher concentration $(2.0 \mathrm{mg} / \mathrm{l})$ of NAA (Thiyagarajan and Venkatachalam, 2013). The present results were supported by the findings of earlier reports (Anitha and Pullaiah, 2002) and (Thiyagarajan and Venkatachalam, 2012), where, auxin IBA was proven to be the superior hormone for the rooting response in a broad series of plant species including Melothria maderaspatana (Baskaran et al., 2009), Benincasa hispida (Thomas and Sreejesh, 2004), and C. sativus (Venkatachalam et al., 2018). It is interesting to point out that in our study, the combination of IBA and BA in a medium resulted in a higher rooting response when compared to IBA alone. The stimulatory role of auxins in promoting the growth of roots has been reported in a number of studies (Naz and Anis, 2012; Aslam et al., 2013), and IBA in particular, has been broadly used to initiate/augment roots in tissue culture-mediated plants (Dipti et al., 2014).

Most recently, Kher and coworkers (2016) reported that a half strength MS medium fortified with $8.05 \mu \mathrm{M}$ $\alpha$-naphthaleneacetic acid augmented the formation of inexhaustible roots in Clerodendrum phlomidis and Althaea officinalis as the addition of $1.0 \mathrm{mg} / 1 \alpha$-naphthalene acetic acid and IBA at $0.5 \mathrm{mg} / 1$ to the medium resulted in the formation of the highest number of roots (Mujib et al., 2017). Hence, in the study, IBA was found to be a superior auxin for rooting in the cucurbitaceae member followed by NAA. The same kind of observation was also recorded in cultivated Cucumis species (Cucurbitaceae member) (Compton et al., 2001; Selvaraj et al., 2002; Venkatachalam et al., 2018).

\section{Acclimatization}

The rooted plantlets with matured leaves were successfully placed in poly cups containing sand and soil in the ratio of $1: 2$ and covered with polythene bags to ensure high humidity. Initially, the plantlets were kept in fully closed and controlled conditions for two weeks and 
the polybags were gradually discarded in order to acclimatize the plantlets to greenhouse conditions. Consequently, the plantlets were transferred to field conditions and the survival rate was $81 \%$ (Fig. 1). The in vitro regenerated plants grew well and were phenotypically similar to the parental stock. Similar results were achieved and reported by Venkatachalam et al. (2018) in C. sativus, by Sheik Mohamed et al. (2017) in A. baccifera and by Kulkarni et al (2000) in W. somnifera.

\section{Conclusions}

Our study was designed to prepare a tissue culture protocol for large scale multiple shoot-bud regeneration from nodal explants of $C$. colocynthis. The highest shoot bud induction (94.9\%) without attaining callus was observed in MS medium supplemented with BA whereas, the combination of plant growth regulators induced more shoots/explant. The protocol for in vitro regeneration presented herein is different from that developed for medicinal plants reported earlier. The results of our study strongly suggest that the pre-eminence of $\mathrm{BA}$ and other cytokinins in combination with $\mathrm{GA}_{3}$, is essential for a swift multiple shoot-bud induction as well as an enhanced rate of shoot proliferation in C.colocynthis. A fullstrength MS medium, supplemented with $1.5 \mathrm{mg} / \mathrm{l}$ IBA combined with $1.5 \mathrm{mg} / \mathrm{l} \mathrm{BA}$, was found to be the best for a maximum rooting response, and the regenerated plantlets were successfully established in field conditions with an $81 \%$ survival rate. The in vitro tissue culture protocol standardized here can be used for commercial (pharmaceutical) scale plant production as well as conservation of this important traditional medicinal plant from possible extinction in the near future.

\section{Acknowledgments}

We are thankful to the management authorities and Principal of Jamal Mohamed College (Autonomous) for providing necessary facilities to carry out this research work.

\section{References}

Afifi M.S., Ross S.A., Elsohly M.A., Naeem Z.E., Halawelshi F.T. (1999) Cucurbitacins of Cucumis prophetarum and Cucumis prophetarum. J. Chem. Ecol. 25: 847.

Ahmad A., Anis M. (2005) In vitro mass propagation of $\mathrm{Cucu}$ mis sativus L. from nodal segments. Turk. J. Bot. 29: 237-240.

Anitha S., Pullaiah T. (2002) In vitro propagation of Decalepis hamiltonii. J. Trop. Med. Plant 3: 227-232.
Arockiasamy D., Muthukumar I.B., Natarajan E., Britto S.J. (2002) Plant regeneration from nodal and internode explants of Solanum trilobatum L. Plant Tiss. Cult. 12: 93-97.

Aslam J., Mujib A., Sharma M.P. (2013) In vitro micropropagation of Dracaena sanderiana Sander ex Mast: an important indoor ornamental plant. Saudi J. Biol. Sci. 20: 63-68.

Atta-Ur-Rahman A., Ahmed V.U., Khan M.A., Zehra F. (1973) Isolation and structure of cucurbitacin. Phytochemistry. 12: 2741.

Barik DP., Naik S.K., Mudgal A., Chand P.K. (2007) Rapid plant regeneration through in vitro axillary shoot proliferation of butterfly pea Clitoria ternatea L.-a twinning legume. In Vitro Cell. Dev. Biol. Plant. 43: 144-148.

Baskaran P., Velayutham P., Jayabalan N. (2009) In vitro regeneration of Melothria maderaspatana via indirect organogenesis. In Vitro Cell Dev Biol Plant. 45: 407-413.

Brassard N., Brissette L., Lord D., Laliberte S. (1996) Elongation, rooting and acclimatization of micropropagated shoots from mature material of hybrid larch. Plant Cell Tiss. Org. Cult. 44: 37-44.

Caldas L.S., Machado L.D.L., Caldas S.C., Campos M.L., Caldas J.A., Pharis R.P. (2009) Growth active gibberellins overcome the very slow shoot growth of Hancornia speciosa, an important fruit tree from the Brazilian Cerrado. Trees Struct. Funct. 23: 1229-1235.

Carmen S.J.M., Ballester A., Vieitez A.M. (2001) Effect of thidiazuron on multiple shoot induction and plant regeneration from cotyledonary nodes of chestnut. J. Hort. Sci. Biotechnol. 76: 588-595.

Compton M.E., Pierson B.L., Staub J.K. (2001) Micropropa gation for recovery of Cucumis hystrix. Plant Cell Tiss. Organ Cult. 64: 63-67.

da Silva J.A.T., Hussain A.I. (2017) Citrullus colocynthis (L.) Schrad.(colocynth): Biotechnological perspectives. Emirates J. Food Agri. 29(2): 83-90.

Dipti T., Fatima S., Mujib A. (2014) Morphological anomalies in somatic embryo structure in Catharanthus roseus: improving embryo germination by amending plant growth regulators, activated charcoal and sucrose level. British Biotechnol. J. 4(1): 10-20.

Elrofaei N.A., Elsharif K.H., Elshikh A.A., Bashir M.E., Ahmed I.F., Garbi M.I., Kabbashi A.S., Saleh M.S. (2018) Studies on antibacterial activity of some medicinal plants against selected bacterial strain. J. Antimicrob. Agents 4: 2 .

Figueiredo S.F.L., Albarello N., Viana V.R.C. (2001) Micropropagation of Rollinia micosa Jacq. Baill. In Vitro Cell. Dev. Biol. Plant. 37: 471-475.

Furmanowa M., Gajdzis-Kuls D., Ruszkowska J., Czarnocki Z., Obidoska G., Sadowska A. (2001) In vitro propagation of Withania somnifera and isolation of withanolides with immunosuppressive activity. Planta Med. 67: 146-149.

Gallily R., Shohat B., Kalish J., Gitter S., Lavie D. (1962) Further studies on the antitumor effect of Cucurbitacins. Cancer Res. 22: 1038.

Gambley R.L, Dodd W.A. (1990) An in vitro technique for the production de novo of multiple shoots in cotyledon ex- 
plants of cucumber (Cucumis sativus L.). Plant Cell Tissue Organ Cult. 20: 177-183.

Ganesan K., Huyop F., (2010) In vitro regeneration of Citrullus lanatus cv. Round dragon. J. Biol. Sci. 10: 131-137.

Gomez K.A., Gomez A.A. Statistical procedure for agricultural research. John Wiley \& Sons, New York, 1984.

Grozeva S., Velkov N. (2014) In vitro plant regeneration of two cucumber (Cucumis sativum L.) genotypes: effects of explant types and culture medium. Genetika 46: 485-493.

Hussain A.I., Rathore H.A., Sattar M.Z.A., Chatha S.A.S., Sarker S.D., Gilani A.H. (2014) Citrullus colocynthis (L.) Schrad (bitter apple fruit): a review of its phytochemistry, pharmacology, traditional uses and nutritional potential. J. Ethnopharmacol. 155: 54-66.

Jesmin R., Mian M.A.K. (2016) Callus induction and efficient plant regeneration in Cucumber (Cucumis sativus L.). J. Biosci. Agri. Res. 9: 796-803.

Jeyakumar M., Jayabalan N. (2002) In vitro plant regeneration from cotyledonary node of Psoralea corylifolia L. Plant Tiss. Cult. 12: 125-129.

Kher M.M., Soner D., Srivastava N., Nataraj M., TeiXiera da Silva J.A. (2016) Micropropagation of Clerodendrum phlomidis L.F. J. Hort. Res. 24(1): 21-28.

Kontas J., Kintzios S. (2003) Developing a scale up system for the micropropagation of cucumber (Cucumis sativus L.). The effect of growth retardants, liquid culture and vessel size. Plant Cell Rep. 21: 538-548.

Kulkarni A.A., Thegane S.R., Krishnamurthy K.V. (1996) Direct in vitro regeneration of leaf explants of Withania somnifera L. Dunal. Plant Sci. 119: 163-168.

Kulkarni A.A., Thengane S.R., Krishnamurthy K.V. (2000) Direct shoot regeneration from node, internode, hypocotyl and embryo explants of Withania somnifera. Plant Cell Tiss Org Cult. 62: 203-209.

Kumar P., Gambhir G., Gaur A., Srivastava D.K. (2015) Molecular analysis of genetic stability in in vitro regenerated plants of broccoli (Brassica oleracea L. var. italica). Curr. Sci. 109: 1470-1475.

Lavie D., Glotter E. (1971) The cucurbitacins, a group of tetracyclic triterpenes. Fortschr. Chem. Org. Naturst. 29: 307.

Meena M.C., Meena R.K., Vidya Patni V. (2010) High frequency plant regeneration from shoot tip explants of $\mathrm{Ci}$ trullus colocynthis (Linn.) Schrad. - An important medicinal herb. J. Pharm. Phytochem. 2(6): 53-56.

Malayaman V., Sisubalan N., Senthilkumar R.P., Sheik Mohamed S., Ranjithkumar R., Ghouse Basha M. (2017) Chitosan mediated enhancement of hydrolysable tannin in Phyllanthus debilis Klein ex Willd via plant cell suspension culture. Int. J. Biol. Macromol. 104: 1656-1663.

Malik K., Saxena P.K. (1992) Regeneration in Phaseolus vulgaris L. high frequency induction of direct shoot formation in intact seedlings by $\mathrm{N} 6$ - benzylaminopurine and thidiazuron. Planta. 186: 384-389.

Miró M. (1995) Cucurbitacins and their pharmacological effects. Phytother. Res. 9: 159.
Mohamed M.F., Read P.E., Coyne D.P. (1991) In vitro response of bean Phaseolus vulgaris L. cotyledonary explants to benzyladenine in the medium. Plant Growth Regul. 19: 19-26.

Mujib A., Pipal T., Ali M., Tonk D., Zafar N., Gulzar B. (2017) In vitro propagation of Althaea officinalis: the role of plant growth regulators in morphogenesis. BioTechnologia 98(3): 167-173.

Murashige T., Skoog F. (1962) A revised medium for rapid growth and bioassays with tobacco tissue culture. Physiol Plant. 15: 473-497.

Naz R., Anis M. (2012) Acceleration of adventitious shoots by interaction between exogenous hormone and adenine sulphate in Althaea officinalis L. Appl. Biochem. Biotechnol. 168: 1239-1255.

Nitsch J.P., Nitsch C. (1969) Haploid plants from pollen grains. Science 163: 85-87.

Ntui V.O., Thirukkumaran G., Lioka S., Mii M. (2009) Efficient plant regeneration via organogenesis in Egusi Melon (Colocynthis citrullus L.). Sci. Hort. 119: 397-402.

Pirinc V., Onay A., Yildirim H., Adiyaman F., Isikalan C., Basaran D. (2003) Adventitious shoot organogenesis and plant regeneration from cotyledonasu of diploid diyarbakir watermelon (Citrullus lanatus cv. "Surme”). Turk. J. Biol. 27: 101-105.

Prakash N.S., Pental D., Bhalla-Sarin N. (1994) Regeneration of pigeon pea Cajanus cajan from cotyledonary node via multiple shoot formation. Plant Cell Rep. 13: 623-627.

Prem Kumar G., Sivakumar S., Siva G., Vigneswaran M., Senthil Kumar T., Jayabalan N. (2016) Silver nitrate promotes highfrequency multiple shoot regeneration in cotton (Gossypium hirsutum L.) by inhibiting ethylene production and phenolic secretion. In Vitro Cell Dev Biol Plant. 52: 408-418.

Raman S., Jaiwal P.K. (2000) In vitro multiplication of Pegamum harmala an important medicinal plant. Indian J. Exp. Biol. 38: 499-503.

Rathore M.S., Mastan S.G., Yadav P., Bhatt V.D., Shekhawat N.S., Chikara J. (2016) Shoot regeneration from leaf explants of Withania coagulans (stocks) Dunal and genetic stability evaluation of regenerates with RAPD and ISSR markers. South Afr. J. Bot. 102: 12-17.

Ray S., Jha S. (2001) Production of withaferin a in shoot cultures of Withania somnifera. Planta Med. 67: 432-436.

Rout G.R. (2005) Micropropagation of Clitoria ternatea Linn Fabaceae-an important medicinal plant. In Vitro Cell. Dev. Biol. - Plant. 41: 516-519.

Selvaraj N., Vasudevan A., Manickavasagam M., Kasthurirengan S., Ganapathi A. (2007) High frequency shoot regeneration from cotyledon explants of cucumber via organogenesis. Sci. Hort. 112: 2-8.

Selvaraj N., Vasudevan A., Manickavasagam V., Ganapathi A. (2006) In vitro organogenesis and plant formation in $\mathrm{cu}$ cumber. Biol. Plant 50: 123-126.

Selvaraj N., Vasudevan A., Prem Anand R., Ramesh Anbazhgan V., Ganapathi A. (2002) Micropropagation of Cucumis 
sativus L. from field grown plants. [in:] Proceedings of $\mathrm{Cu}$ curbitaceae conference. Naples: 149-156.

Sen J., Sharma A.K. (1991) Micropropagation of Withania somnifera from germinating seeds and shoot tips. Plant Cell Tiss Org Cult. 26: 71-73.

Sheik Mohamed S., Sisubalan N., Malayaman V., Ghouse Basha M. (2017) High frequency and reproducible plant regeneration from nodal explants of Ammannia baccifera L. a folkloric medicinal plant for the production of vital compounds. Int. J. Bot. Stud. 2(6): 129-136.

Singh J., Tiwari K.N. (2012) In vitro plant regeneration from decapitated embryonic axes of Clitoria ternatea L. An important medicinal plant. Industr. Crops Prod. 35: 224-229.

Siva G., Sivakumar S., Prem Kumar G., Vigneswaran M., Vinoth S., Arunachalam S., Elango B., Senthil Kumar T., Jayabalan N. (2015) Multiple shoot production from nodal explants and FTIR analysis of in vitro regenerated plants of Psoralea corylifolia L. Pharm. Biol. Eval. 2: 105-109.

Sivanandhan G., Mariashibu T.S., Arun M., Rajesh M., Kasthurirengan S., Selvaraj N., Ganapathy A. (2011) The effect of polyamines on the efficiency of multiplication and rooting of Withania somnifera L. Dunal and content of some withanolides in obtained plants. Acta Physiol Plant. 33: $2279-2288$.

Thiruvengadam M., Jayabalan N. (2000) Mass propagation of Vitex negundo L., In vitro J. Plant Biotechnol. 2: 151-155.

Thiyagarajan M., Venkatachalam P. (2013) A reproducible and high frequency plant regeneration from mature axillary node explants of Gymnema sylvestre Gurmur-An important antidiabetic endangered medicinal plant. Ind. Crops Prod. 50: 517-524.

Thiyagarajan M., Venkatachalam P. (2012) Large scale in vitro propagation of Stevia rebaudiana Bert. for commercial application. Pharmaceutically important and antidiabetic medicinal herb. Ind. Crops Prod. 37: 111-117.

Thomas T.D., Sreejesh K.R., (2004) Callus induction and plant regeneration from cotyledonary explants of ash gourd (Benincasa hispida L.). Sci. Hort. 100: 359-367.

Ugandhar T., Venkateshwarrlu M., Begum G., Srilatha T., Jaganmohanreddy K. (2011) In vitro plant regeneration of
Cucumber (Cucumis sativum L.) from cotyledon and hypocotyl explants. Sci. Res. Rep. 1: 164-169.

Vasudevan A., Selvaraj N., Ganapathi A., Choi C.W., Manickavasagam M., Kasthurirengan S. (2007) Direct plant regeneration from cucumber embryonal axis. Biol. Plant. 51: 521-524.

Vasudevan A., Selvaraj N., Ganapathi A., Kasthurirengan S., Ramesh Anbazhagan V., Manickavasagam M. (2004) Glutamine: a suitable nitrogen source for enhanced shoot multiplication in Cucumis sativus L. Biol. Plant. 48: 1215-1218.

Vengadesan G., Selvaraj N., Prem Anand R., Gaba V., Ganapathi A. (2005) Ontogeny of somatic embryos in Cucumber (Cucumis sativus L.). In Vitro Cell Dev. Biol. Plant. 41: 789-793.

Venkatachalam P., Jinu U., Sangeetha P., Geetha N., Sahi S.V. (2018) High frequency plant regeneration from cotyledonary node explants of Cucumis sativus L. cultivar 'Green Long' via adventitious shoot organogenesis and assessment of genetic fidelity by RAPD PCR technology. 3 Biotech. 8: 60. https://doi.org/10.1007/s13205-018-1083-8.

Vivekanandan L., Amzad Basha K., Edwin Raj E., Sisubalan N., Ghouse Basha M. (2014) In vitro regeneration and evaluation of genetic stability of Rubia cordifolia L.: An endangered medicinal plant of Pachamalai Hills, Tamil Nadu, India. Eur. Acad. Res. 2(7): 10016.

Wang S.L., Seong S.K., Ye X.G., He C.F., Suk Y.K., Pil S.C. (2015) Current status of genetic transformation technology developed in cucumber (Cucumis sativus L.). J. Integrat. Agric. 14: 469-482.

Yadav J.P., Kumar S., Siwach P. (2006) Folk medicine used in gynecological and other related problems by rural population of Haryana. Indian J. Traditional Knowledge 5(3): 323-326.

Zhao F., Wang R., Xue J., Duan Y. (2018) Efficient callus-mediated regeneration and in vitro root tuberization in Trichosanthes kirilowii Maxim., a medicinal plant. In Vitro Cell. Dev. Biol. Plant. https://doi.org/10.1007/s11627-0189932- z. 